\title{
BEYOND L2 GRAMMAR INSTRUCTION
}

\author{
Miroslava Tsvetkova ${ }^{1}$
}

\begin{abstract}
Language acquisition is an ontogenetic, hierarchical, and complex process. In 1957, the psychologist B. F. Skinner, as a pioneer of behaviourism, described linguistics through human behavior in his book Verbal Behaviour and explained the learning of a language. Two years later, in 1959, Noam Chomsky criticized his proposal and the learnability of a language. He believed that language is an innate ability and for this reason he established the term "acquisition" to substitute "learning".The constructivists, on the other hand, suggested that children were sensitive to patterns in the target language which enabled the acquisition process.
\end{abstract}

Recent language acquisition trends include the cognitive approach that can foster grammar acquisition. The article has tutorial nature, addressing recent advances in cognitive perception. The analysis of Bulgarian students' questionnaires reveals the tendency in the students' expectations to shift language acquisition to the cognitive constructivist approach, based on the work of Jean Piaget (2001) who argues that cognitive development precedes language. The article aims at investigating the barriers the students face while acquiring second language grammar structures rather than studying what they will learn. Besides their cognitive perception, students rely on their internal constructions of knowledge. They themselves construct their knowledge through experience as well as through communication. As Vygotsky (1978) states thought and language become linked through communication.

Key words: acquisition, learning, cognition, cognitive constructivist approach

\section{Introduction}

Two main positions can be distinguished when talking about the acquisition of language. On one hand, some argue (Chomsky, 1959; Skinner, 1957) that children are born with an innate ability to learn languages. Chomsky (2012) believes that language acquisition is a gradual build-up of knowledge that increases competence within the language. According to the same author, the cognitive approach allows the student to make mistakes and study from them.

On the other hand, other linguists believe that children construct their language depending on the input (Scheffler, 2015). Piaget (2001) believes that learners construct their language through experience. Unlike Piaget, Vygotsky (1978) believed that children construct their knowledge through social interaction,

1. Assistant Prof., PhD at Shumen University, Department of English Studies, Shumen, Bulgaria, e-mail: m.tsvetkova@shu.bg 
"learning is a necessary and universal aspect of the process of developing culturally organized, specifically human psychological function" (1978, p. 90).

Both Piaget (2001) and Vygotsky's (1978) theories of learning have been used to explain the methods that are regularly used in learning a language at an early age. When we compare and contrast them, we can easily see their understanding of cognitive development. The difference between them is that Piaget believes independent self-learning is essential while Vygotsky argues that learning should be directed by a teacher. When both theories are used together, there is a great opportunity to help children develop critical thinking skills and cognitive awareness.

Figure 1 shows the relationship between language and thought, expressed in the theories of different researchers. The language determines what we can see. The language is also our "mental organ". Thus, learning a second language can broaden our view of the world.

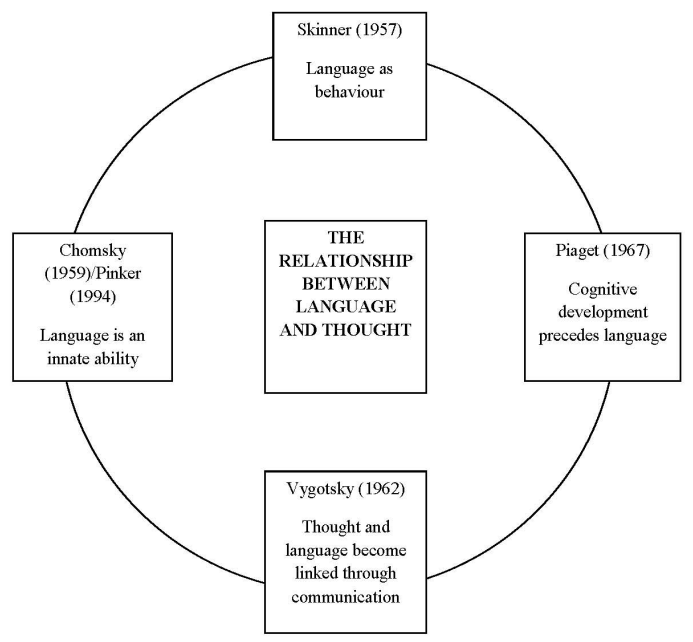

Figure 1. The relationship between language and thought.

According to Boers and Lindstromberg (2008), the cognitive approach emphasizes the constructing of linguistic knowledge and rules.

The article argues that the relationship between the psycholinguistic reality of language and the student's production of the target language can foster students' efficient learning and their ability to use the foreign language.

\section{Aim and research questions}

The aim of the paper is to explore the possibilities of the cognitive approach to foster EFL teaching and learning and investigate the barriers primary education 
students face while acquiring second language grammar structures. As a result, the following research questions arose:

- Can the cognitive EFL model of teaching foster the learning of a foreign language?

- Is practice necessary to grasp the grammar of a language?

\section{Methodology}

\section{The learning environment}

With respect to the EFL university context, the cognitive approach tends to resolve the linguistic knowledge gaps. That is why, the deductive way of teaching was well supplemented.

The teacher structured the lessons according to the cognitive dimensions in learning foreign languages focusing on metalinguistic awareness, cognitive competence, and knowledge structuring skills to develop students' target knowledge and skills.

Students were exposed to English as the target language and as a result this provided a source of modelling in regards to the production of the language.

\section{Research design}

The experimental learning was implemented for 6 weeks (6 sessions), from November 2018 till December 2018, at the Faculty of Education, Konstantin Preslavsky University in Shumen, Bulgaria. The teaching model included 1 initial lesson, 4 study lessons, and 1 test per group. The classes were held twice a week and the overall number of academic hours per group was 12. Data were collected with the help of a pre-test, a post-test, and a questionnaire in both groups involved in the study.

\section{Participants}

The focus group included 16 students, taking their second and third year at the university. The participants were divided into a control group (CG) and an experimental group(EG). The learners from both the control and the experimental groups took a basic course of training within the university's Bachelor program, Primary school education with a foreign language (English).

\section{Description of the teaching framework}

The study aimed at improving students' linguistic competence and overcoming the barriers they face while acquiring second language grammar structures by means of the cognitive approach. The sessions included a variety of activities with collaborative (peer-to-peer or in larger groups) and independent learning to obtain a set of skills or knowledge. 
The teaching of both groups dealt with the same grammar units, skills, and learning materials but they were taught in different models.

In the traditional teaching model the focus was on language acquisition through the inductive way of language and grammar presentation. Thus, in teaching the control group the traditional methodology was used in conducting the drills, translation in the classroom was allowed, and written language was developed. The students used mainly textbooks and workbooks in their work - Straightforward Intermediate Student's Book/Workbook and Straightforward Upper-Intermediate Student's Book/Workbook respectively for the third- and fourth-year students.

The cognitive teaching model, on the other hand, also contained elements of the traditional teaching model but the important part was the cognitive-based strategy. It followed Kecskes' conceptual fluency framework (Kecskes \& Papp, 2000) which focused on meaningful learning and practice. The activities aimed at developing cognitive drills to master the acquired knowledge.

In the experimental group the additional cognitive-based tasks included comprehending linguistic concepts and deriving rules, inference of knowledge, structuring, and applying the new grammar units. Spoken target language (English) was used in the classroom.

The activities which the students of the experimental group completed were designed to stimulate substitution, mutation, and transformation drills.

Using mutation drills students had to change the form of words using the inflections of verbs and nouns. The agreement between the constituent parts in a sentence was also practised in this type of activities.

Transformation drills involved learners in consciously manipulating language patterns, which raised their awareness of structure. Students had to change the word order, add or delete grammatical constituents, change sentences from affirmative to negative, from active to passive voice, from indicative to interrogative, imperative, or subjunctive mood, and from simple to compound or complex sentences.

\section{Data collection and data presentation}

The aim of the study is to find the way to organize learning to foster the development of cognitive skills in EFL students. Quantitative and qualitative data were obtained through communication activities during the experiment and survey questionnaires. The analyses for this study compare outcomes for students in the experimental group with their counterparts in the control group at the beginning and immediately after the experimental learning.

Data presentation included questions, suggesting either a multiple choice or a free answer, which the students completed. 


\section{Discussion}

The use of grammar was assessed in CG and EG. The number of the acquired grammar units at the end of the sessions in CG was 3, while in EG it was 8. The results show higher gain in EG by 5 . The difference between the number of the acquired units in each group at the beginning and the end of the experimental learning was also significant: for CG it was 2, whereas for EG it was 7, which proves the greater impact of the cognitive teaching model on the learners' language acquisition.

The majority of students, both from the CG and the EG, pointed out in the questionnaires negative factors, which, however, are due to the educational conditions, while the positive changes in the EG could be assigned to the use of the cognitive teaching model.

Here are some questions that were asked:

Are you satisfied with what you have learned?

Did you enjoy your learning?

What was difficult for you?

What kind of activities did you like?

The students from EG said that they liked speaking in the target language when assisting each other on issues they did not understand, when asking the teacher for some explanation, and when completing a task. Five students from CG preferred speaking in the mother tongue because they did not want to make mistakes. They were afraid of misunderstanding the instructions.

Most students from EG indicated that they faced challenges with grammar while others pointed out that they struggled with parts of speech. Three students from CG mentioned that they had problems with grammar, especially passive voice, reported speech, and use of tenses. Two students from the same group said they needed more help in constructing conditional sentences, as well as they had difficulties with subject and verb agreement. Three students from EG said they did not encounter any problems.

Traditional exercises, such as gap-filling, multiple choice, and open the brackets, were used in the control group. Generally, there are numerous barriers to learning a second language, such as environment, age, motivation, or exposure to English. But the most important aspect in CG was the mother tongue, which affected second language learning, especially grammar, negatively.

In the experimental group the traditional exercises were replaced by substitution, mutation, and transformation drills, which required a certain amount of thinking. Morphemes and syntax were the main barriers the students from EG had to overcome in learning English as a second language. However, the present study 
did not look at morphemes and syntax as linguistic components on their own, rather at whether students lack the skills to apply them in writing and speaking in English or not.

The results show that the acquisition of the target knowledge in EG can improve students' linguistic competence.

Students needed to learn how to ask questions and listen carefully when a person replied. The teacher had to bring students out of themselves by creating a supportive environment. Role-play was used in the classroom in activities such as conversations with friends, talking on the telephone at work or asking for help in dangerous situations.

Understanding the cognitive processes involved in L2 production is a key factor for determining if teaching is adequate to the psycholinguistic reality of language processing in production. In order to understand how L2 production works, we first need to understand how L1 operates. In this way, we can easily explain the negative transfer from the mother tongue. The present article follows Willem Levelt's model of L1 production (Levelt, 1993) which describes the processofspeakingfromintention to articulation.

There are two reasons for choosing Levelt's model. Firstly, it has been the most influential model in L2 production research. Therefore, it permits comparisons with explanations and findings made in other studies. Secondly, Levelt's production model is relevant to this study because it complements the explanation of other processes which mediate language processing such as attention and memory.

Levelt's model (1993) consists of a number of components which are responsible for different aspects of speech production. It starts with the conceptualizer. It is responsible for generating the communicative intention. The declarative knowledge is used to encode it in what is about to be said.

Later on, in the formulator, the process of grammatical encoding begins with the retrieval of lexical items from the mental lexicon. Lexical items are retrieved with the information that is relevant for the construction of the syntactic environment of the word. The second step of formulating is morphological and phonological encoding.

In the articulator the phonetic and articulatory plan is executed. The product of articulation is overt speech.

Levelt's model reveals a number of incongruities with the dominant teaching paradigm. First, as the model demonstrates, lexis and grammar represent an inseparable unity. Moreover, speech is lexically driven in that lexical components precede syntactic processing. In the meantime, most of the foreign language textbooks treat grammar and lexis separately and fail to reflect this crucial 
characteristic of speech production. Second, in Levelt's model, grammar is tied to individual words, i.e. it is stored in lexical entries and constitutes part of the speaker's lexical knowledge. This seems to run counter to the commonplace practice of using generalized rules in instruction: learners are usually provided with the rules that apply to a group of words. Thus, the explicit knowledge of generalized rules will be applied to specific language and will become implicit through practice (Ellis, 1993).

\section{Conclusion and implications}

Levelt's model points to the critical role of cognition but although most aspects of L2 production can be explained by models of L1 production, we have to explain some peculiarities of L2 speech as well.

In the meantime, the emphasis on the cognitive aspect of language learning encourages students to create the language while applying the rules at the same time. The above incongruities may be attributed to the fact that the dominant teaching paradigm relies on Generative (Chomskyan) Linguistics (Ellis, 2001). According to Generative Linguistics, the mind has a module for language acquisition - language acquisition device (LAD) - that is uniqueand separate from the rest of cognition. Knowledge about language, according to this view, is "competence grammar", a complex set of rules and constraints that allows people to distinguish grammatical from ungrammatical sentences (Ellis, 1998).

The study tried to determine how the activities and approaches to learning English can overcome the barriers to improve language skills.

As a result, at the end of the sessions, students spoke with enthusiasm, their accent and pronunciation were not affected by their mother tongue. The grammar they used was satisfactory although there were still some mistakes.

The cognitive constructivist framework provided a variety of activities to challenge students, enhance their learning, help them to discover new ideas and construct their own knowledge. It is the researcher's opinion that lots of issues need to be considered in the process of learning - the purpose, time, syllabi, teaching and learning methods.

As the experimental study demonstrated, traditional instruction needs much time to explain the meaning of new language items, as it is based on using only the target language in the classroom. The cognitive approach, on the other hand, permits using the mother tongue, eliminating obstacles for students' efficient and successful experience. The topic, learning materials and the set of activities in both teaching models created a challenging and motivating learning environment for widening students' linguistic knowledge, but the cognitivebased model helped the teacher to provide a more efficient and rich context in 
which students can exchange ideas and investigate problems. Thus, the designed cognitive model of teaching created opportunities to enhance EFL teaching.

Implications for EFL methodology from this study suggest that cognitivebased approach to teaching can be used effectively in designing a motivating, enjoyable and effective learning environment.

\section{References:}

Boers, F., \& Lindstromberg, S. (Eds.) (2008). Cognitive linguistic approaches to teaching vocabulary and phraseology. Berlin: Mounton de Gruyter.

Cameron, L. (2001). Teaching languages to young learners. Cambridge University Press.

Chomsky, N. (1959). Review of Skinner's Verbal Behavior. Language. 26-58.

Chomsky, N. (2012). The Science of Language. Interview with James McGilvray. Cambridge University Press.

Ellis, R. (1993). The structural syllabus and second language acquisition. TESOL Quarterly, Vol. 27, No. 1, 91-113.

Ellis, N. (1998). Emergentism, connectionism and language learning. Language Learning, 48, 631-664.

Ellis, R. (2001). Introduction: Investigating form-focused instruction. Language Learning 51, 1-46.

Kecskes, I., \& Papp, T. (2000). Foreign language and mother tongue. Hillsdale, NJ: Lawrence Erlbaum.

Kerr, P., \& Jones, C. (2012). Straightforward. Second edition. Intermediate Student's Book. Oxford: Macmillan Education.

Kerr, P., \& Jones, C. (2012). Straightforward. Second edition. Upper-Intermediate Student's Book. Oxford: Macmillan Education.

Kerr, P., \& Jones, C. (2012). Straightforward. Second edition. Upper-Intermediate Workbook. Oxford: Macmillan Education.

Levelt, W. (1993). Speaking: From intention to articulation. MIT Press.

Lighthouse, B. (2012). The communicative approach in education. Novel chapters. https:// brianlighthouse.wordpress.com/.../the-communicative-approach-i...24 July 2013.

Piaget, J. (2001). The psychology of intelligence. Oxford, UK: Routledge.

Pinker, S. (1995). The New Science of Language and Mind. Penguin.

Scheffler, P. (2015). Introducing very young children to English as a foreign language. International Journal of Applied Linguistics, Vol. 25, Issue 1, 1-22.

Skinner, B. F. (1957). Verbal behavior. New York: Appleton Century Crofts.

Vygotsky, L. S. (1978). Mind in society: The development of higher psychological processes. Cambridge, MA: Harvard University Press.

Waterman, J. (2012). Straightforward. Intermediate Workbook. Second edition. Oxford: Macmillan Education. 